\title{
Relações técnicas e estéticas entre os cinemas do pós- Segunda Guerra e o cinema digital com base no filme Timecode
}

\section{João Paulo de Carvalho dos Reis e Cunha}

Universidade de Sorocaba, Programa de Pós-graduação em Comunicação e Cultura, Sorocaba, SP, Brasil ORCID: http://orcid.org/0000-0003-4467-7438

\section{Maria Ogécia Drigo}

Universidade de Sorocaba, Programa de Pós-graduação em Comunicação e Cultura, Sorocaba, SP, Brasil ORCID: http://orcid.org/0000-0002-5123-0610

\section{Resumo}

As relações técnicas e estéticas entre o cinema moderno, cujas correntes tomaram impulso no período pós-Segunda Guerra, e o cinema digital, produzido a partir da segunda metade dos anos 1990, é o tema deste artigo. Objetiva-se identificar as características do filme Timecode (2000) e relacioná-las, por uma linha evolutiva, com aproximações e distanciamentos, às principais correntes do cinema moderno - experimental, direto e disnarrativo. Paralelamente, abordamos as especificidades da hipermídia e do cinema digital contemporâneos. Entre os resultados, destaca-se que o cinema digital dos anos 1990 foi um desdobramento das inovações trazidas pelo cinema moderno.

\section{Palavras-chave}

Cinema. Cinema digital. Hipermídia. Múltiplas telas. Timecode.

\section{Introdução}

Este artigo apresenta, inicialmente, as correntes do cinema moderno surgidas após a Segunda Guerra Mundial, na perspectiva de Parente (2000). Nesta obra, o autor discute três delas: o cinema experimental, o qual, dentre as várias tendências e concepções que o termo abarca, envolve inovações e abordagens não tradicionais dos processos fílmicos ou narrativos; o direto que, em linhas gerais, caracteriza-se por envolver a estética do real, ou 
seja, por questionar as fronteiras entre o real e a ficção, a vida e a representação; e o disnarrativo com seus múltiplos pontos de vista sobre situações e personagens que permutam posições entre protagonismo/antagonismo, sujeito/objeto e cujo tempo narrativo se funda constantemente durante a projeção. Em seguida, trata da ascensão do vídeo digital como recurso técnico para produção de obras cinematográficas, valendo-nos, para tanto, de Machado (1997) e Manovich (2001). Por fim, estão as reflexões sobre o filme Timecode, de Mike Figgis, realizado em vídeo digital e que está entre a produção de cinema digital da virada do século XX para XXI.

Objetiva-se, portanto, identificar as especificidades do filme Timecode (2000) e, em seguida, investigar como e em que medida as características técnicas e estéticas deste filme estão imbricadas, explicitando aproximações e distanciamentos, às correntes do cinema moderno.

\section{0 cinema moderno e suas correntes}

Parente (2000), em Narrativa e modernidade: os cinemas não-narrativos do pósguerra, trata dos cinemas experimental, direto e disnarrativo, enfatizando a deficiência da semiologia - ciência associada ao estudo da significação em textos verbais, mas à qual a crítica cinematográfica é comumente submetida - em dar conta das especificidades da narrativa no cinema moderno.

Iniciamos com a corrente do cinema experimental.

\subsection{0 cinema experimental}

Parente (2000) inicia sua exposição denunciando a falta de unidade no uso do termo "experimental" por parte dos próprios teóricos e críticos deste cinema, os quais, fundamentados na semiologia, projetam os conceitos e funções da comunicação linguística à análise fílmica, normalmente incorrendo, por conta disso, em falsas oposições para diferenciar o tradicional do experimental: um cinema do significado, do sentido, da comunicação e da narração versus um cinema criativo, poético, que privilegia "momentos formais", estes ligados à aparência sensível ou à estrutura da obra, a despeito de qualquer sentido que ela venha a veicular. 
Observa-se, ainda, que tal falta de unanimidade se reflete até em determinar historicamente as origens do cinema experimental: para uns, foi com o "cine-olho", conceito desenvolvido pelo cineasta soviético Dziga Vertov e apresentado em filmes como Um homem com uma câmera (1929). Para outros, com as vanguardas francesas dos anos 1920; alguns ainda remetem essas origens a Méliès ou mesmo aos irmãos Lumière. Consequentemente, um grande número de filmes foi reunido de forma artificial sob o título de "experimental", atribuído sem muita preocupação conceitual, devido a razões históricas, desconhecimento ou outros que não os próprios processos de realização fílmica.

Parente (2000, p. 88) esclarece que um filme pode ser chamado de experimental se traz contribuições "para o aperfeiçoamento, o avanço ou a renovação do cinema e de sua linguagem". Assim, depois de 1920, experimental "é aquele que tem por objetivo a descoberta de um cinema 'puro', no sentido de que está liberado de tudo o que não é especificamente fílmico" (PARENTE, 2000, p. 88).

Em seguida, o mesmo autor esclarece que o cinema experimental explicitou três tendências que, embora díspares, são classificadas como relativas ao experimental devido à aplicação, pelos críticos, de conceitos secundários ao cinema, os de significação linguística, que tendem a reduzir esta corrente a uma simples oposição à narratividade do cinema clássico.

A primeira tendência, a única que se pode chamar de fato de não-narrativa, é a do "cinema-matéria" ou "acinema", que leva a concepção de "cine-olho" de Vertov ao extremo. Nas palavras de Parente (2000, p. 94):

\footnotetext{
0 "cine-olho" implica o ultrapassamento do olho humano rumo a um olho não-humano, que estaria nas coisas. [...] Ele é objetivo no sentido em que introduz a percepção nas coisas e na matéria, de maneira que qualquer ponto do espaço varie ou perceba todos os outros sobre os quais ele age ou que agem sobre ele, sem fronteiras nem distância.
}

Isto implica, conforme Parente (2000, p. 95), que "não podemos passar de uma imagem a outra: não há mais intervalo de movimento, nem de ação, nem de reação. Isso significa dizer que a relação entre imagens é incomensurável do ponto de vista da percepção humana".

Os cineastas modernos que alcançaram notoriedade na prática deste tipo de cinema experimental, em particular nos Estados Unidos, Kubelka, Breer, Snow, Belson, Landow, 
Brakhage, entre outros, extrapolam as imagens-movimento rumo ao seu material energético - o fotograma -, explorando associações de luzes, cores, sons, oscilações de velocidades, vibrações e granulações, por vezes chegando a pintar ou gravar as imagens à mão na própria película.

A segunda tendência do cinema experimental é o que se convencionou chamar de "cinema-subjetivo", ou "filme de transe", "filme onírico", "fantasmático", que surgiu nos anos 1920 sob influência dos movimentos de vanguarda artística (futurismo, expressionismo, impressionismo, surrealismo, etc.) e se estendeu até a década de 1940, com a vanguarda e o underground americanos, sendo que nestes últimos se destacaram filmes de Deren, Petterson, Broughton, Harrington, Markopoulos e Linder, entre outros.

Tais obras têm como característica comum episódios em que o personagem se vê imobilizado diante de situações-limite, sensações visuais e sonoras ou perturbações psicomotoras, como paralisia, sono, sonho, hipnose, alucinação e efeito de drogas. Portanto, os movimentos cinematográficos que surgiram a partir de alianças variáveis com os diversos "ismos" das vanguardas artísticas apresentam procedimentos fílmicos que visam traduzir esteticamente estados alterados de consciência, justaposição e confusão constante entre real e imaginário, passado e presente, realidade mental e realidade sensível, valendose para isso de efeitos como fusões, superposições, anamorfoses, movimentos aberrantes de câmera, efeitos de cenário e de laboratório, entre outros.

Contudo, Parente (2000) questiona por que muitos críticos e teóricos categorizaram como "experimentais" filmes das vanguardas artísticas, quando realizados por cineastas norte-americanos e não fizeram o mesmo em relação aos europeus, os quais, além de frequentemente os terem precedido em desenvolver tais estéticas, fizeram-no introduzindo inovações de fato nos processos fílmicos. Ousamos oferecer uma resposta. De um lado, os filmes com frequência inserem-se em movimentos, formando um conjunto que compartilha características e, em geral, se constitui em um contexto geográfico e historicamente definido. De outro, ao se consolidarem em sua filmografia local e obtendo aceitação perante o público e a crítica, podem fundar tendências capazes de se propagar e influenciar cineastas de outras partes. Essa transposição de movimentos cinematográficos, de um contexto onde ele havia surgido de maneira "orgânica" para outro onde foi introduzido posteriormente, pode causar no segundo um efeito de estranhamento, por abalar modelos e padrões estéticos já consagrados. Dessa forma, tornam-se "experimentais" por apresentarem regimes do olhar e processos fílmicos diversos perante novos públicos, 
habituados com outras tradições cinematográficas. Esse processo de transposição ocorre constantemente e, conforme veremos mais adiante, o próprio cinema digital dos anos 1990 recupera e remete a várias experiências e tendências apresentadas ou praticadas pelo cinema moderno.

Por fim, Parente (2000) discute a terceira tendência do cinema experimental, o "cinema do corpo". Nesta tendência, conforme Parente (2000, p. 105-106):

[...] os corpos são afetados pelo tempo, pela duração (presente vivo) de tal maneira que exprimem uma pluralidade das maneiras de ser no presente. Não é tanto que os corpos não ajam mais. Mas suas ações - a balada, a conversa, a dança, a espera, o voyeurismo etc. - não são mais determinadas em relação ao espaço hodológico, vivido, homogêneo e causal. Os corpos tornam-se imagens óticas e sonoras puras indeterminadas ou, então, um jogo de máscaras.

Tem-se, assim, no cinema de Warhol, Morrissey, Varda, Duras, Akerman, entre outros, e mesmo de precursores como Bresson, Antonioni, Fellini, Pasolini, Rivette, Godard, Rocha e Cassavetes, uma exposição do corpo cotidiano, nos preparativos de uma cerimônia, na espera; enfim, uma teatralização ou espetacularização das atitudes e posturas do corpo.

Mesmo não sendo o "cinema-sonho" e o "cinema do corpo" invenções do experimental, representando tendências gerais do cinema, quando se leva em conta a inovação, segundo Parente (2000, p. 107), "poder-se-ia, então, dizer que o cinema experimental é o cinema em que a vontade artística está no comando. Nesse sentido, é experimental o cinema dos verdadeiros criadores, quaisquer que sejam eles".

Vejamos as especificidades do cinema direto.

\subsection{0 cinema direto}

Esta corrente, assim como o cinema experimental, recobre tendências cinematográficas bastante distintas, como o "free cinema", o "candid eye", o "living-camera", o "cinema de comportamento", o "cinema-verdade", o "cinema espontâneo" e o "cinema vivido", os quais tiveram suas origens principalmente na França, na Inglaterra e nos Estados Unidos, entre o fim dos anos 1950 e início dos 60. Em linhas gerais, o cinema direto é o que tem como proposta filmar diretamente a realidade vivida e o real, e, para tanto, segundo seus críticos, englobaria "uma técnica (películas $16 \mathrm{~mm}$ sensíveis, câmara leve, som sincronizado etc.), um método de filmagem (ausência de roteiro, equipe reduzida, atores 
não profissionais, som direto, câmera na mão, cenários naturais etc.) e uma estética, 'a estética do real"' (PARENTE, 2000, p. 112).

De acordo com os teóricos e entusiastas do cinema direto, chegar-se-ia a essa estética graças à evolução das técnicas, que permitiriam ao cineasta "mergulhar" no real, captando-o de forma não-intrusiva e sem interferência, segundo modelo fornecido pela própria realidade, daí o termo "direto". Com isso, passou-se a privilegiar os movimentos de câmera e os planos-sequência, que permitiam ao cineasta "montar" o filme durante a filmagem, ao invés de construí-lo posteriormente no processo de montagem tradicional.

Contudo, conforme explica Parente (2000), esses pressupostos de registro imparcial da realidade evocados pelos teóricos do direto constituem uma visão bastante dogmática e limitada das relações entre realidade e seu registro ou representação, uma vez que, fundamentalmente, o real não tem duplo, pois é singular (não representativo). Logo, um cinema que se pretende apreendê-lo diretamente denuncia ter ideias preconcebidas ou préformatadas dele - ao cabo, um "modelo do mundo", no qual endossa os clichês da pura representação e da significação que lhe é pressuposta.

Dessa forma, a estética do real busca fazer ver e ouvir as relações entre o homem e uma dada situação sobre a qual age para mudá-la ou melhorá-la, mas, ainda que o enredo narrado não tenha sido criado pelo cineasta (trate-se de uma história "real", o que a aproxima do documentário ou da reportagem), utiliza-se dos mesmos recursos do sistema de representação clássica do cinema de ação, exprimindo as confrontações entre o homem (por vezes tomado como personagem-modelo ou "herói") e o mundo.

Se a estética do real se constitui como uma primeira tendência do cinema direto, a esta opõe-se uma segunda, a do "cinema espelho". Em determinados filmes, o realizador coloca pessoas reais para "interpretarem" suas próprias vidas. Posteriormente, gravam com elas sua voz, comentando as imagens de sua atuação e unindo-as no filme. Tem-se, por conseguinte, uma duplicação entre uma imagem visual e uma imagem sonora, em que os protagonistas se tornam espectadores da própria vida, ultrapassando sua situação e atingindo a verdade dessa vida, com o filme tornando-se um espelho em que o personagem descobre a si próprio no jogo entre real e ficção.

Nesta tendência, em que o cinema direto se torna "indireto" por apresentar um personagem que se vê representar a si próprio, os acontecimentos e personagens não preexistem ao filme, tal como nos documentários, reportagens ou filmes da primeira tendência. 
As personagens não remetem aos modelos preestabelecidos. 0 filme não consiste em ligar as personagens a uma situação, mesmo real, tomada de improviso, ou a uma intriga preexistente. Pouco importa, portanto, que as personagens ou as situações sejam reais ou fictícias. (PARENTE, 2000, p. 121-122).

Assim, o filme torna-se o próprio acontecimento, tendo sua importância deslocada para uma função reveladora do desenvolvimento do personagem, o qual se constitui a cada gesto, cada fala e cada comportamento, coincidindo este progresso com a própria duração do filme. Nesse processo, afirma-se o tempo no presente à medida que o protagonista passa a ficcionar e representar a si próprio, sem nunca ser fictício, tornando-se ainda mais real, justamente por não negar a ficção como potência e como modelo preconcebido do real. Ao longo desse percurso, são capazes de inventar e fundar uma imagem vívida de um povo, de uma comunidade, de uma minoria, baseada na ficção que criam sobre si.

Rouch, Clarke, Warhol, Morrissey, Perrault, Guerra, Cony-Campos, Rivette e Cassavetes, entre outros cineastas, que desenvolveram filmes seguindo esta tendência, criaram filmes que eram produzidos por grupos de pessoas que eram também personagens. Tais obras, Parente (2000) designa por "indireto livre", pois o espetáculo torna-se documento e a ficção, ficção sobre uma representação. Como consequência, inversamente temos a afirmação da vida, quando os personagens representam a sua própria (colocando a si mesmos em uma condição de alteridade) para que ela não apareça como ficção, esvaziando a artificialidade do espetáculo e tornando indiscernível o limite entre o real e o imaginário. "O acontecimento é a verdadeira improvisação do cinema indireto. Ele é ainda mais real quando é menos significante, ainda mais presente quando destrói e des-realiza sua realização espaço-temporal, e ainda mais verdadeiro quando é menos fundado" (PARENTE, 2000, p. 125).

Enfim, segundo Parente (2000), o que importa nesse cinema direto-indireto não é remeter a uma situação real ou, menos ainda, ao uso de determinados recursos técnicos que configuram a "estética do real", uma vez que a técnica é sucessora do ato de criação: o que o define de fato é justamente o questionamento da fronteira que separa a vida da representação.

Vejamos a terceira tendência, o cinema disnarrativo. 


\subsection{0 cinema disnarrativo}

O termo "disnarrativo" foi lançado em 1975 pelo romancista e cineasta francês Alain Robbe-Grillet (1922-2008), expoente tanto do nouveau roman (novo romance) quanto do nouveau cinéma (novo cinema). Nas palavras de Parente (2000, p. 131):

O disnarrativo tem por objetivo quebrar não a ilusão da narrativa, mas a ilusão da narrativa como modelo de verdade, ou seja, sua lógica causal (uma sequência causal de acontecimentos: um vem após o outro e por causa do outro), sua referencialidade (a narrativa como reprodução ou relação do que acontece ou do que aconteceu) e sua transparência (ela não reproduz, mas representa ou reporta o que aconteceu).

Se de um lado o cinema disnarrativo de Robbe-Grillet rompe com uma estrutura temporal fundada na linearidade causal entre acontecimentos, não visa, por outro, eliminar o tempo da narrativa, abolir o tempo cronológico ou investir em uma estrutura acrônica de leis e modelos. Pelo contrário, é um cinema que busca aprofundá-lo e afirmá-lo, um tempo que se funda e constrói dinamicamente ao longo do filme. Esse cinema implica uma mutação estrutural: não há mais uma estrutura fundamental que sub-ordena cronologicamente uma série narrativa, mas sim, uma telestrutura profunda e geradora de uma série que se transforma em outra e, nessa passagem, geram uma terceira, a expressão da relação estabelecida entre as anteriores: "[...] as relações de tempo ou a coexistência das durações na imagem e os sistemas de tempo, inúmeros e coexistentes, da narrativa tornaram-se as principais personagens do cinema moderno" (PARENTE, 2000, p. 136). Tem-se, assim, conforme afirma Fontanari (2017, p. 281), uma estrutura cíclica, pois "as ações já não se organizam tendo em vista um fim, ou seja, não há mais a preocupação de criar obstáculos, que vão pouco a pouco sendo superados e concluídos numa tentativa de marcar o término da história, como ocorre na narrativa tradicional".

Como desdobramento, a própria função dos personagens dentro da narrativa sofre mutações. Neste ponto, Parente (2000) evoca o linguista lituano A. J. Greimas (1966) ${ }^{1}$, que definiu as posições cardeais dos participantes ativos em uma narrativa: sujeito (aquele que pratica a ação), objeto (o que sofre a ação), destinador (que proporciona a ação), destinatário (a quem a ação será dirigida), coadjuvante (que facilita a ação) e oponente (quem a dificulta). Enquanto no cinema narrativo clássico há personagens ocupando

${ }^{1}$ GREIMAS, Algirdas Julius. Sémantique structurale. 1. ed. Paris: Larousse, 1966. Apud Parente (2000). 
posições normalmente bem específicas, no caso do cinema disnarrativo, ao se considerar uma das séries, há personagens ocupando posições cardeais definidas como sujeito, objeto, etc. Tomando-se outra série, pode haver uma total permutação entre esses lugares, contradizendo, negando ou até mesmo anulando as ocorrências da série anterior.

\begin{abstract}
Essa é uma das características das narrativas de Robbe-Grillet, mas também de muitas narrativas do cinema moderno - transgredir a regra permutando as funções cardeais. No cinema disnarrativo, o sujeito e o objeto são indiscerníveis. Os actantes não têm identidade, pois ocupam todas as posições na narrativa. Eles são tudo a um só tempo. (PARENTE, 2000, p. 134).
\end{abstract}

Essa indeterminação das ações e dos personagens em um mundo descontínuo e fragmentado é visível em filmes de Robbe-Grillet, como Trans-Europ-Express (1966) e O jogo com o fogo (1975), assim como em obras de Orson Welles como Grilhões do passado (1955) e História imortal (1968). Essas obras atestam uma luta de cada personagem "para conquistar a palavra narradora, e cada palavra narradora se esforça para destituir uma autoridade" (PARENTE, 2000, p. 136). Ao cabo, cada personagem busca fundar o tempo, seu presente, e inventar sua narrativa ao mesmo tempo em que age.

A produção de sentidos no cinema disnarrativo, evidentemente, repercute essa constituição volátil de personagens, ações e séries temporais. Segundo Parente (2000), nos filmes de Robbe-Grillet, o sentido não é dado ou representado, rompendo com a tradição do cinema clássico de uma "verdade" ou "realidade" preexistente a ser desvelada. "Há um sentido, mas ele não se revela obviamente, ele acena, roça, fazendo um certo apelo, como se quisesse dizer algo, sem, no entanto, forçosamente dizê-lo" (FONTANARI, 2017, p. 288).

Por conseguinte, o espectador, que no cinema clássico é o centro para quem o filme se dirige, vê-se desconcertado diante de um deslizar de imagens que passam a falar para si próprias, constituindo uma colagem serial e atonal de fragmentos e uma narrativa da ordem do "improvável" ou "inexplicável". Tais efeitos, em termos técnicos, são atingidos com o uso de "diversas manipulações, explorando as diferentes possibilidades oferecidas pela montagem, a composição, o cromatismo, o enquadramento, os movimentos de câmera e outras técnicas" (FONTANARI, 2017, p. 282).

Após apresentarmos as correntes do cinema moderno e as tendências que as compõem, veremos, a seguir, as características do filme Timecode (2000), um breve histórico do advento do cinema digital na década de 1990, no qual esta obra se inscreve, 
suas influências imediatas das mídias e sistemas informáticos para, então, investigarmos como e em que medida a técnica e a estética do referido filme envolve as transformações introduzidas pelo cinema moderno.

\section{Timecode: o cinema digital e suas relações com o moderno}

Timecode (2000), do diretor inglês Mike Figgis, é, em linhas gerais, uma comédia dramática de humor negro que conta a história de um grupo de personagens, que se encontram em uma produtora de cinema de Los Angeles durante os preparativos para um filme, e deles emerge uma rede de intrigas amorosas e traições.

Utilizando-se da tecnologia das câmeras de vídeo digital (DV), que teve seu apogeu entre a segunda metade da década de 1990 e início dos anos 2000, a obra apresenta como principal elemento - o que a distingue da linguagem tradicional do cinema -, o fato de ser apresentada com a tela dividida em quadrantes. Trata-se de uma única história, que ocorre em tempo real, e é apresentada simultaneamente na tela em quatro telas menores que exibem, em cada uma delas, pontos de vista captados por uma câmera. Cada uma acompanha os personagens de cada quadrante, em um único e ininterrupto plano-sequência na duração do filme (97 minutos), em um fluxo contínuo de imagens, sendo que a narrativa está circunscrita à duração, sem elipses ou cortes. As câmeras sempre estão na mão dos cinegrafistas, sem uso de tripés, o que garante ao filme uma dinâmica de mudanças constantes de ângulos e enquadramentos, em cada quadrante. Em dados momentos, inclusive, as situações se cruzam e, então, pode-se vê-las, ao mesmo tempo, em dois quadrantes diferentes, sob duas perspectivas.

Devido a essa opção estética, o filme não apresenta propriamente uma "montagem", na acepção clássica do termo, com uma construção temporal linear de planos que se sucedem individualmente na tela via cortes, e que ao cabo constitui tradicionalmente a base da narrativa cinematográfica. Contudo, a indicação de uma leitura linear pelas quatro telas está presente e é dada pelo som, que prioriza a ação de maior importância em cada momento (segundo a elaboração lógica proposta pelo diretor do filme), aumentando o volume dessa e baixando o das outras.

Apesar de o diretor ser o responsável por conduzir a ação nas cenas, determinar o movimento e o enquadramento das câmeras e direcionar o olhar para as imagens através do som, cabe ao espectador a prerrogativa de selecionar para qual tela dar atenção, segundo 
seus próprios critérios de interesse. 0 percurso de seu olhar proporcionará uma seleção de fragmentos do filme que ao final será única, construindo assim uma experiência de narrativa visual individualizada.

O uso do vídeo digital como recurso técnico para realização de filmes para cinema, contudo, não surgiu com Timecode. Os longas cinematográficos feitos em vídeo digital tiveram um primeiro marco com o Dogma95 (2019), manifesto criado pelos cineastas dinamarqueses Thomas Vinterberg e Lars von Trier, em 1995. 0 manifesto, além de um conjunto rígido de regras, denominado "Votos de Castidade", iniciou um movimento estético que se espalhou, nos anos seguintes, muito além do território dinamarquês. Entre essas regras, estão as de que as gravações devem ser feitas em locação, não em estúdio; o som deve ser ambiente, nenhuma adição, mesmo de trilha sonora, seria permitida, à exceção de músicas diegéticas; a câmera deve ser sempre operada na mão, sem outros tipos de apoio ou maquinário; os filmes devem ser a cores e com luz natural; filtros de lente ou outros dispositivos óticos são proibidos; os filmes não devem conter ação superficial, como armas e assassinatos; e a ação deve ocorrer no momento presente e no local em que ocorrem (não se permitem filmes de época ou locações que mimetizem outras). Todas essas regras deviam ser aplicadas para se obter um cinema mais "verdadeiro", sem o ilusionismo e manipulação criados pelos diversos recursos técnicos disponíveis à realização cinematográfica.

Os filmes que se enquadravam nessas regras recebiam uma espécie de "selo de aprovação", que atestava seu pertencimento ao movimento. 0 primeiro deles foi Festa de família (1998). 0 principal legado deste movimento foi apresentar e preparar realizadores e plateias para esta nova linguagem e forma de se fazer filmes. As câmeras digitais, segundo Hanson (2003), por seu tamanho reduzido, permitiam maior mobilidade e demandavam equipes menores, baixando assim o custo das produções, embora oferecessem baixa resolução de imagem em comparação com a película fotográfica do cinema tradicional.

Timecode não foi produzido para enquadrar-se nas regras do Dogma 95, mas a sua produção atende a algumas delas como câmera na mão, luz natural, cenas feitas todas em locação e ação no tempo e espaço presentes, mas burla outras, pois apresenta cena de assassinato e música incidental.

Mas a tecnologia digital não influenciou apenas tecnicamente os equipamentos para captação de imagens e processos de produção de filmes para cinema. A presença dos computadores nas diversas atividades do dia a dia fez com que a estética de suas interfaces gráficas, com múltiplas janelas simultâneas, fosse incorporada à cultura e criasse uma nova 
convenção visual que não tardaria a se propagar para outras mídias, como canais televisivos de notícias (Bloomberg, GloboNews) e jogos de videogame.

No caso do cinema, Timecode é um dos exemplos mais representativos dessa tela em mosaico que sintetiza a convergência da sensibilidade e da visualidade contemporâneas. Machado (1997) define como "hipermídia" as obras que se fundamentam nessa estrutura combinatória.

\begin{abstract}
A hipermídia permite justamente exprimir tais situações complexas, polissêmicas e paradoxais, que uma escritura sequencial e linear, plena de módulos de ordem, teria muito mais dificuldades de representar. Um documento hipermidiático jamais exprime um conceito, no sentido de uma verdade dada por uma linha de raciocínio; ele se abre para a experiência plena do pensamento e da imaginação, como um processo vivo que se modifica sem cessar, que se adapta em relação ao contexto, que, enfim, joga com os dados disponíveis. (MACHADO, 1997).
\end{abstract}

Os filmes com telas divididas abrem-se para o vagar do olhar, deixando o espectador livre para percorrer as várias imagens e encontrar entre elas seus elementos de interesse, nos quais fixar sua atenção. Tal experiência pode ser enriquecedora, pois permite que o espectador atue, não de maneira interativa (uma vez que não lhe é possível interferir diretamente no conteúdo do filme), mas de maneira participativa e não prevista ao criar sua própria montagem linear temporal e, assim, finalizar a obra.

A esta forma de montagem, Manovich (2001) chama de montagem espacial: diferentemente da montagem temporal tradicional, largamente teorizada e praticada ao longo do século XX e cuja técnica envolve a sucessão de imagens uma de cada vez ao longo do tempo. A montagem espacial ocorre entre imagens que coexistem na superfície da tela, acessíveis ao espectador ao mesmo tempo. Contudo, o autor enfatiza que a simples justaposição de várias imagens simultaneamente não resulta em montagem: esta, para ocorrer, depende de uma lógica estabelecida pelo diretor do filme para determinar quais imagens aparecem juntas, quando elas aparecem e quais as relações passíveis de estabelecerem entre si.

Vejamos como as características do cinema digital apresentadas no filme Timecode se relacionam, em termos de aproximações e distanciamentos, com as correntes do cinema moderno do pós-guerra. 


\subsection{Aproximações do cinema experimental com Timecode}

Experiências com narrativas cinematográficas que utilizam telas divididas começaram décadas antes da realização de Timecode. Ainda que a tecnologia digital lhes tenha dado um novo impulso a partir dos anos 1990, o pioneiro das trucagens e efeitos especiais no cinema, Georges Méliès, nos primeiros anos do século XX, inseria quadros menores dentro da imagem; Abel Gance já utilizava a técnica de split screen (tela dividida) em seu filme Napoleão (1927), assim como o cineasta experimental norte-americano Stan Van der Beek, nos anos 1960. Há outros exemplos pontuais de filmes que utilizam esse recurso em algumas cenas: a abertura de Os imorais (1990), de Stephen Frears; Confidências à meia-noite (1959), em que a tela é dividida entre os personagens de Rock Hudson e Doris Day durante suas conversas telefônicas; e, de uma maneira metafórica, Janela indiscreta (1954), de Alfred Hitchcock, em que o personagem de James Stewart, imobilizado em uma cadeira de rodas devido a uma perna quebrada, observa seus vizinhos cujos prédios lhe fazem fundo, sendo que sua própria janela aludiria à tela do cinema, e cada janela dos vizinhos, que exibem a "narrativa" de suas vidas, corresponderiam a telas menores.

Timecode (2000), contudo, distingue-se desses exemplos porque adota a estética da tela dividida durante toda a duração e se apoia na construção da linearidade narrativa por meio do passeio livre do olhar do indivíduo, que compõe uma montagem particular.

Se este filme é narrativo, considerando-se que o enredo é conduzido pelas ações de seus personagens, tendo ainda o olhar do espectador como o centro da experiência, isso imediatamente o afasta da primeira tendência do cinema experimental, o "cinema-matéria". Conforme vimos, esta é caracterizada justamente por ser não narrativa, devido à relação entre suas imagens representar uma variação universal descentrada e, por conseguinte, uma percepção pura que estaria nas coisas e seria anterior à percepção humana.

Tampouco o filme em questão possui qualquer identidade com o "cinema-subjetivo", uma vez que não apresenta personagens em situações visuais e sonoras que remetam a "imagens-sonho", ou estados alterados de consciência. Assim como também não investe na teatralização de corpos, atitudes e gestos dos personagens, tal como no "cinema do corpo" da terceira tendência.

Isso tudo, porém, não indica que não há nada que se possa considerar experimental em Timecode. Anteriormente, fizemos uma oferta de resposta ao questionamento de André Parente sobre por que os filmes relacionados a diversos movimentos de vanguarda artística, 
quando realizados por cineastas norte-americanos, receberam a classificação de "experimentais", mas não suas contrapartes europeias, mesmo que estas últimas tenham criado de fato novos processos fílmicos e tenham precedido os primeiros em adotar tais estéticas. Argumentamos que, ao serem transpostas de seu local e contexto histórico de origem para outro, certos movimentos se tornam "experimentais" por apresentarem regimes do olhar e processos fílmicos diversos perante novos públicos, habituados com outras tradições cinematográficas. Ora, defendemos que esse é o mesmo caminho percorrido por Timecode: ainda que não tenha criado a narrativa em múltiplas telas, recuperou-a dentre as diversas experiências que o precederam, mas no contexto da tecnologia digital.

Nesse ponto, levou-a às telas dos cinemas e a apresentou para um novo público, que começava a se habituar com as múltiplas janelas das interfaces gráficas computacionais como uma das tendências das poéticas tecnológicas da contemporaneidade. Enfim, conforme afirmou Parente (2000, p. 107), "é experimental o cinema dos verdadeiros criadores, quaisquer que sejam eles", por colocarem a vontade artística no comando. Dessa forma, o diretor Mike Figgis utilizou a tecnologia digital não só para recriar experiências do passado, mas também para se colocar novos desafios na confecção de uma obra em sintonia com a técnica e a estética de seu tempo.

\subsection{Aproximações do cinema direto com Timecode}

O cinema direto, como vimos, tem como proposta filmar a realidade, valendo-se de processos que os teóricos do direto chamaram de "estética do real". Trata-se de mergulhar no real, de modo não-intrusivo e sem interferência.

Porém, o filme de que ora tratamos é claramente uma obra ficcional, sem compromisso de retratar uma história baseada em fatos reais. Mas, tal "estética do real", que surgiu entre os anos 1950-60, influenciou o cinema de ficção nas décadas seguintes, desde os filmes hollywoodianos de grande orçamento, até os que se utilizam de técnicas mais modestas, entre eles o cinema digital dos anos 1990. Este último, em sua origem, valeu-se das mesmas inovações técnicas que impulsionaram o direto (câmeras leves, equipes reduzidas) para constituir seu próprio estatuto: por exemplo, os "Votos de Castidade" do movimento Dogma 95, citados anteriormente, ecoam vários dos princípios norteadores da 
"estética do real" (câmera na mão, gravações em locação, luz natural, situações no tempo presente) - técnicas de que Timecode (2000) também se vale.

Além dessas, este filme ainda se alinha à "estética do real" pelo uso dos planossequência ininterruptos e por não haver montagem entre planos, somente enquadramentos e reenquadramentos da própria câmera em movimento.

Quanto às outras duas tendências do cinema direto, "cinema-espelho" e "cinema indireto livre", elas têm em comum personagens que interpretam a si mesmos e se veem interpretar, compondo um jogo de espelhos ou de máscaras que afirmam a vida à medida que esvaziam a artificialidade do espetáculo e tornam indiscerníveis o real e o imaginário, libertando-se de um modelo de verdade.

Em Timecode, os atores (todos profissionais) interpretam personagens que (supõese) não têm relação com sua própria vida e personalidade, de forma que, em princípio, o filme se distancia dessas tendências. Porém, não podemos ignorar o fato de ser um filme metalinguístico, pois trata dos bastidores de uma produtora de cinema e dos personagens pitorescos que a compõem. Evidentemente, não é possível medir o quanto os atores e o diretor basearam-se em personalidades e situações "reais" de uma produtora para desenvolver os personagens. A metalinguagem imprime no filme algo de revelador sobre si próprio, no sentido visto no "cinema-espelho". Ao fazer uma ficção sobre si mesmo, seja de forma mais crítica e ácida como o filme em questão, seja como em outros que pretendem passar uma visão mais idealizada ou "glamourizada", insinua-se, ainda que de maneira sutil ou enviesada, o imaginário de seus realizadores sobre o próprio meio, de forma que se perde de vista o limite entre a ficção e a realidade, entre a pura criação e representação ou a inspiração em fatos e pessoas "reais", imbuídas em maior ou menor grau de idealização.

\subsection{Aproximações do cinema disnarrativo com Timecode}

Conforme discutimos, o cinema disnarrativo rompe com a ilusão da narrativa como modelo da verdade, as relações causais, a referencialidade e a transparência na representação dos acontecimentos. Como consequência, elimina o tempo cronológico, mas, contrariamente, torna-se um cinema que funda e constrói o seu próprio tempo dinamicamente ao longo do filme, refletindo-se, inclusive, na composição de seus personagens, que permutam suas funções cardeais entre as diversas séries narrativas, ora afirmando, ora negando ou, ainda, anulando suas ações anteriores. 
Timecode, por outro lado, apresenta uma narrativa absolutamente linear, haja vista que é realizado em tempo real, com sua história tendo a duração do filme, sem elipses, captada pelas quatro câmeras simultâneas em planos-sequência ininterruptos. Por essa descrição, poder-se-ia imaginar que este filme é o avesso do disnarrativo, com o qual não teria nenhum ponto de contato. Pelo contrário, a relação entre ambos, aparentemente inexistente segundo a definição tradicional desse tipo de cinema, ocorre em sua estrutura profunda, na relação entre as quatro telas e na participação do espectador, alinhada à hipermídia contemporânea.

Para entendermos como se opera a disnarratividade neste filme, precisamos primeiramente buscar a definição de imagem-cristal de Deleuze (1990). Para o filósofo, a imagem-cristal é uma imagem atual que possui uma correspondente virtual, dupla, especular. No entanto, segundo Deleuze (1990), as posições de atual e virtual não são fixas, mas mútuas, reversíveis, recíprocas e se alternam ao redor de um ponto de indiscernibilidade, sendo irredutíveis e indivisíveis entre si. Ele denomina de "circuito cristalino" a dinâmica de alternância de posição entre imagens num binômio atual-virtual.

No filme há diversas ocorrências de circuitos cristalinos em imagens que se duplicam de maneira especular no mesmo quadro. Há as cenas em que o personagem Lester Moore, o diretor do "filme dentro do filme", faz testes de câmera com as atrizes, pois elas são vistas encenando na profundidade do quadro (imagem atual), enquanto suas imagens são exibidas ao mesmo tempo em uma tela de TV que está em primeiro plano. Há ainda os circuitos que se formam com as relações amorosas: a traição, tripla por natureza, envolve a disputa de dois personagens para atrair a atenção de um terceiro. Os dois primeiros constroem uma relação especular, ainda que por oposição (vemos tal situação nos trios entre os personagens Emma-Alex-Rose e Lauren-Alex-Rose).

Há, portanto, uma aproximação entre os personagens de Timecode e os personagens descontínuos do cinema disnarrativo, pois eles permutam suas funções cardeais entre sujeito e objeto, destinador e destinatário, à medida que passam de traidores a traídos, dominadores a submissos, ofensores a vítimas. Isso não ocorre, contudo, por permutarem posições em séries distintas, como no disnarrativo, mas por cambiarem os papéis que desempenham nas relações pessoais.

Vimos, anteriormente, que no disnarrativo, os personagens lutam entre eles para fundar seu próprio tempo e impor sua palavra sobre as outras. No filme em questão, contrariamente, essa voz que se impõe é "doada" pelo narrador (o diretor), nos momentos 
em que aumenta o volume de uma das imagens e baixa o das outras, deixando-os em segundo plano. Contudo, o que ele não consegue é justamente "calar" as imagens, que permanecem presentes. Logo, é possível que qualquer uma delas venha atrair o olhar do público. Dessa forma, são as imagens, e não os personagens, que se impõem ao espectador.

Mas é em outra instância da imagem-cristal que se apoia a disnarratividade de fato. Segundo Deleuze (1990), o cristal nos permite, ao cabo, ver um fluxo circular do tempo: passado e presente tornam-se contemporâneos, formando entre si um circuito cristalino, em que se atualizam dinamicamente.

0 cristal, com efeito, não para de trocar as duas imagens distintas que o constituem, a imagem atual do presente que passa e a imagem virtual do passado que se conserva: distintas e no entanto indiscerníveis, e indiscerníveis justamente por serem distintas, já que não se sabe qual é uma e qual a outra. (DELEUZE, 1990, p. 102).

Podemos associar a esta definição do cristal a fundação constante do tempo no cinema disnarrativo, com suas séries não-lineares, causais ou cronológicas, as quais representam presentes e passados que coexistem como possíveis.

As múltiplas telas de Timecode, por sua vez, alinham-se à lógica do acúmulo de imagens simultâneas das telas computacionais, assim como a dos bancos de dados, onde informações são armazenadas e ficam acessíveis a qualquer momento. Somadas aos planossequência ininterruptos do filme, as relações que esses elementos podem estabelecer entre eles com a montagem espacial correspondem a uma operação de atualização, de constituição de um presente na forma de uma série que passa e se desfaz, ao passo que as imagens que não entraram na seleção permanecem coexistindo simultaneamente na tela, referindo-se a um "passado em geral", virtual, externo à consciência do espectador, mas ao qual ele pode dirigir-se novamente para efetuar uma nova atualização e iniciar uma nova série. 0 espectador, inclusive, que no cinema disnarrativo da modernidade era deixado "de fora" da obra (pois as imagens passavam a "falar para si mesmas"), readquire sua centralidade na contemporaneidade digital, que valoriza a participação do indivíduo na obra, pois passa a ser sua prerrogativa fundar o tempo no filme com a seleção e a combinação de fragmentos que usa para compor suas próprias séries. Nas palavras de Machado (1997): 
Com a obra combinatória, a distribuição dos papéis na cena da escritura se redefine: os polos autor/leitor, produtor/receptor se trocam de forma muito mais operativa. 0 texto hipermidiático é a própria expressão dessa inversão de papéis, em que o leitor recupera [...] o seu papel fundante como cocriador e contribui decididamente para realizar a obra.

A disnarratividade em filmes com múltiplas telas, portanto, extrapola a formação de séries temporalmente fragmentadas, em termos de uma montagem linear temporal, abarcando também a fragmentação do olhar entre os elementos visuais da imagem como parte fundamental de sua formação e de suas possibilidades interpretativas, uma vez que nas artes hipermidiáticas contemporâneas, com suas múltiplas informações visuais e sonoras, a "imagem se oferece agora como um 'texto' para ser 'decifrado' ou 'lido' pelo espectador e não mais como paisagem a ser contemplada" (MACHADO, 1997).

\section{Considerações finais}

O filme Timecode (2000) recuperou, do cinema experimental, a estética da tela dividida em quadrantes, introduzindo-a no contexto digital na confluência com o visual das interfaces gráficas e com a montagem espacial; do cinema direto, toma a "estética do real", com a mobilidade das câmeras digitais ainda mais leves e a necessidade de equipes ainda mais reduzidas, bem como a metalinguagem do filme tangencia o conceito de "cinema espelho", pois, mesmo sendo declaradamente uma obra de ficção, reflete sobre suas próprias condições de produção. E por fim, apesar de Timecode valer-se de uma estrutura temporal absolutamente linear, do cinema disnarrativo incorporou a permutação de posições de seus personagens, subvertendo funções cardeais estanques. Ademais, as combinações de imagens feitas pelo olhar do espectador entre os quadrantes e a conservação de múltiplas imagens na tela remetem respectivamente a uma série presente que passa e a um passado que permanece visível como potencial para novas combinações, representando, a seu modo, um fluxo alinhado à fundação de uma imagem-cristal.

Contudo, dentro do escopo deste artigo, referimo-nos apenas a obras dos movimentos e correntes do cinema moderno e suas relações com o cinema digital enquanto "filmes de cinema", destinados à exibição pública em salas, não contemplando as relações entre o cinema moderno e a evolução da imagem eletrônica e de obras produzidas em outros meios, como a televisão e o vídeo (analógicos e, posteriormente, digitais). Fica aberta, assim, a possibilidade de expansão para uma discussão sobre como o cinema moderno 
influenciou as diversas linhas das artes eletrônicas, dentre as quais o próprio Timecode pode se inserir novamente como um vértice.

Os movimentos e correntes do cinema moderno lançaram inovações sobre os processos fílmicos, formas de abordagem da realidade e composição de estruturas temporais. Estas constituíram novos regimes do olhar e gestos poéticos, os quais se incorporaram ao pensamento e ao fazer cinematográfico e influenciaram, ora de forma mais tangencial, ora de forma mais evidente, a estética do cinema digital. A partir das nossas reflexões sobre Timecode, enfatizamos que as obras desse período se constituíram como um corpo cinematográfico com características próprias, mas que mantiveram um diálogo com o cinema do pós-guerra ao atualizá-lo para o contexto hipermidiático contemporâneo.

\section{Referências}

CONFIDÊNCIAS à meia-noite. Direção: Michael Gordon. Produção: Ross Hunter; Martin Melcher e Edward Muhl. Intérpretes: Rock Hudson, Doris Day, Tony Randall; Thelma Ritter; Nick Adams; Julia Meade; Allen Jenkins; Marcel Dalio; Lee Patrick et al. Roteiro: Stanley Shapiro e Maurice Richlin. Música: Frank De Vol. EUA: Arwin Productions, 1959. 1 DVD (102 min), mono, widescreen, color.

DELEUZE, Gilles. A imagem-tempo: Cinema 2. 1. ed. São Paulo: Brasiliense, 1990.

DOGME95.dk. A tribute to the official Dogme95, Copenhague, 2019. Disponível em: http://www.dogme95.dk. Acesso em: 20 nov. 2019.

FESTA de família. Direção: Thomas Vinterberg. Produção: Birgitte Hald. Intérpretes: Ulrich Thomsen; Henning Moritzen; Thomas Bo Larsen; Paprika Steen et al. Roteiro: Thomas Vinterberg e Mogens Rukov. Música: Lars Bo Jensen. Dinamarca/Suécia: Nimbus Film Productions, 1998. 1 DVD (105 min.), estéreo, fullscreen, color.

FONTANARI, Rodrigo. Nouveau cinéma e o cinema experimental de Alain Robbe-Grillet. Revista ECO-Pós, Rio de Janeiro, v. 20, n. 1, p. 276-292, 2017.

GRILHÕES do passado. Direção: Orson Welles. Produção: Orson Welles e Louis Dolivet. Intérpretes: Orson Welles; Michael Redgrave; Patricia Medina; Akim Tamiroff et al. Roteiro: Orson Welles. Música: Paul Misraki. França/Espanha/Suíça: Mercury Productions, 1955. 1 DVD (93 min.), mono, fullscreen, $\mathrm{p} \& \mathrm{~b}$.

HANSON, Matt. The end of celluloid: film futures in the digital age. 1. ed. Mies: RotoVision, 2003.

HISTÓRIA imortal. Direção: Orson Welles. Produção: Micheline Rozan. Intérpretes: Jeanne Moreau; Orson Welles; Roger Coggio; Norman Eshley e Fernando Rey. Roteiro: Orson Welles 
e Louise de Vilmorin. França: Office de Radiodiffusion Télévision Française, 1968. 1 DVD (58 min), mono, widescreen, color.

JANELA indiscreta. Direção: Alfred Hitchcock. Produção: Alfred Hitchcock. Intérpretes: James Stewart; Grace Kelly; Wendell Corey; Thelma Ritter; Raymond Burr et al. Roteiro: John Michael Hayes. Música: Franz Waxman. EUA: Alfred J. Hitchcock Productions, 1954. 1 DVD (112 min.), mono, fullscreen, color.

MACHADO, Arlindo. Pré-cinemas \& pós-cinemas. 6. ed. Campinas: Papirus, 1997. E-book.

MANOVICH, Lev. The language of new media. 1. ed. Cambridge: MIT Press, 2001.

NAPOLEÃO. Direção: Abel Gance. Produção: Henri de Cazotte; Hugo Stinnes e Wengoroff. Intérpretes: Albert Dieudonné; Vladimir Roudenko; Edmond Van Daële; Alexandre Koubitzky; Antonin Artaud; Gina Manès; Suzanne Bianchetti et al. Roteiro: Abel Gance. Música: Arthur Honegger. França: Films Abel Gance, 1927. 330 min. silencioso, fullscreen, $\mathrm{p} \& \mathrm{~b}$.

O JOGO com o fogo. Direção: Alain Robbe-Grillet. Produção: Georges Dybman. Intérpretes: Jean-Louis Trintignant; Philippe Noiret; Anicée Alvina; Sylvia Kristel et al. Roteiro: Alain Robbe-Grillet. Música: Michel Fano. França/Itália: Arcadie Productions; Madeleine Films e Cinecompany, 1975. 1 DVD (112 min.), mono, widescreen, color.

OS IMORAIS. Direção: Stephen Frears. Produção: Robert A. Harris; Jim Painter e Martin Scorsese. Intérpretes: Anjelica Huston; John Cusack; Annette Bening et al. Roteiro: Donald E. Westlake. Música: Elmer Bernstein. EUA/Canadá: Cineplex Odeon Films, 1990. 1 DVD (110 min.), estéreo, widescreen, color.

PARENTE, André. Narrativa e modernidade: os cinemas não-narrativos do pós-guerra. 1. ed. Campinas: Papirus, 2000.

TIMECODE. Direção: Mike Figgis. Produção: Mike Figgis e Annie Stewart. Intérpretes: Stellan Skarsgård; Jeanne Tripplehorn; Salma Hayek; Saffron Burrows; Holly Hunter; Richard Edson et al. Roteiro: Mike Figgis. Música: Mike Figgis e Anthony Marinelli. EUA: Columbia TriStar Home Video, 2000. 1 DVD (97 min.), estéreo, widescreen, color.

TRANS-EUROP-EXPRESS. Direção: Alain Robbe-Grillet. Produção: Samy Halfon. Intérpretes: Jean-Louis Trintignant, Marie-France Pisier, Christian Barbier et al. Roteiro: Alain RobbeGrillet. Música: Michel Fano. França: Como Films, 1966. 1 DVD (105 min.), mono, widescreen, $\mathrm{p} \& \mathrm{~b}$.

UM HOMEM com uma câmera. Direção: Dziga Vertov. Roteiro: Dziga Vertov. URSS:

Vseukrainske Foto Kino Upravlinnia (VUFKU), 1929. 1 DVD (68 min.), silencioso, fullscreen, $\mathrm{p} \& \mathrm{~b}$. 


\title{
Technical and aesthetic relations between post-World War II cinemas and digital cinema based on the film Timecode
}

\begin{abstract}
The technical and aesthetic relations between modern cinema, whose currents were propelled in the post-World War II period, and digital cinema produced in the mid-1990's is the subject of this article. The objective is to identify the characteristics of the film Timecode (2000) and relate them, in an evolutionary line, through convergences and divergences, to the main currents of modern cinema - experimental, direct and disnarrative. In addition, we approach the specificities of hypermedia and contemporary digital cinema. Among the conclusions, we highlight that digital cinema of the 1990's was a development of the innovations brought by modern cinema.
\end{abstract}

\section{Keywords}

Cinema. Digital cinema. Hypermedia. Multiple screens. Timecode.

\section{Autoria para correspondência}

João Paulo de Carvalho dos Reis e cunha

joaopcrc@gmail.com

\section{Como citar}

CUNHA, João Paulo de Carvalho dos Reis e; DRIGO, Maria Ogécia. Relações técnicas e estéticas entre os cinemas do pós-Segunda Guerra e o cinema digital como base no filme Timecode. Intexto, Porto Alegre, $\mathrm{n}$. 52, e-99843, jan./dez. 2021. DOI: http://dx.doi.org/10.19132/1807-8583202152.99843

Recebido em 24/01/2020

Aceito em 29/03/2021

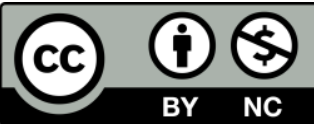

